\title{
A FILOSOFIA DO DIREITO NO SISTEMA FILOSÓFICO DE HEGEL ${ }^{1}$
}

\author{
Pedro Geraldo Aparecido Novelli ${ }^{2}$
}

\section{Resumo:}

A filosofia hegeliana se apresenta como um avanço em relação às outras filosofias enquanto se propõe a acolher em si todas as outras manifestações. Desse modo Hegel pretende realizar seu empenho filosófico na direção do estabelecimento de um sistema filosófico. Trata-se de uma compreensão reconhecida e explicitada por Hegel em sua tese de doutoramento, isto é, de que filosofia somente se faz possível enquanto sistema. Nesse sentido o tratamento dispensado a qualquer uma de suas obras evoca necessariamente a relação com as demais. Uma obra tomada isoladamente deixa a sensação de que algo mais deveria estar presente, porém toda obra de Hegel também contempla a relação com as outras obras. Nesse sentido o que se objetiva aqui é considerar a Filosofia do Direito de Hegel no sistema filosófico hegeliano buscando explicitar seu lugar específico assim como seu transitar por entre as obras do pensador como um todo. A Filosofia do Direito encontra seu momento particular no âmbito do espírito objetivo ou no momento da efetivação do espírito subjetivo. No entanto, assume-se aqui a perspectiva de que a Filosofia do Direito representa, assim como é o espírito objetivo, um momento de mediação assim como um devir pelo qual a efetivação do espírito absoluto se daria. Além disso, a Filosofia do Hegel representa, conforme se entende aqui, a explicitação do que Hegel considera de fundamental importância na filosofia que é, precisamente, a necessidade de se suprassumir a separação entre o homem e o mundo. Não basta, para Hegel, a afirmação do ser nem do pensar em si mesmos, mas se exige a confirmação destes no seu ser outro que se evidenciará ser ele mesmo. Desse modo a filosofia se dá como uma reconstrução ou como o saber de fato enquanto ciência deixando de ser tão somente amor pelo saber. Isso significa em outras palavras que a filosofia lida com o mundo, no mundo e pelo mundo sendo muito mais que uma fala para o mundo para ser a fala do próprio mundo. Se a filosofia é a coruja de Minerva que sempre chega atrasada ela o faz para que aí as razões do outro sejam reconhecidas.

Palavras-chave: Filosofia Hegeliana, Sistema, Espírito Objetivo.

\begin{abstract}
:
The Hegelian philosophy is presented as a progress in relation to other philosophies and it offers to take in itself all the other demonstrations. Thereby, Hegel intends to carry out his philosophical effort towards the establishment of a philosophical system. It is a comprehension recognized and exposed by Hegel in his doctoral thesis, i.e., that philosophy only becomes possible as a system. In this sense, the treatment dispensed to

\footnotetext{
${ }^{1}$ Dedicado ao amigo João Carlos Madoglio pela sua presença num dos momentos mais importantes da minha vida.

${ }^{2}$ Professor Assistente Doutor do Departamento de Educação do Instituto de Biociências, Campus de Botucatu e do Programa de Pós-graduação em Filosofia, Campus de Marília da Universidade Estadual Paulista Júlio de Mesquita Filho - UNESP. E-mail: pnovelli@ibb.unesp.br.
} 
each one of his works necessarily evokes a relationship with all other. An work taken in isolation gets the feeling that something else should be presented, however, every work written by Hegel also contemplates a relation with his other works. In this sense, the objective here is to considerate Hegel's Philosophy of Law in his philosophical system seeking to explicit its specific place, as well as its transit among the works of the thinker as a whole. The Philosophy of Law finds its particular moment in the ambit of the objective spirit or during the subjective spirit's effectuation. However, it is assumed here the perspective that the Philosophy of Law represents, as the objective spirit does, a moment of mediation as well as a there-being whereby the absolute spirit's effectuation would happen. Furthermore, Hegel's Philosophy represents the presentation of what he considers as extremely important in philosophy, that is precisely, the need to sublate the separation between man and the world. It is not enough for Hegel, the affirmation of the being and the thinking in itself, but it is required to confirm them in their being other that will be evinced being itself. Thus, Philosophy is given as a reconstruction or as the factual knowledge as a science ceasing to be so only love of learning. This means in other words that philosophy deals with the world, in the world and for the world being much more than a speech to the world to be the talk of the world itself. If philosophy is the owl of Minerva who always arrives late, she does it for the reasons of the other to be recognized.

Keywords: Hegel's Philosophy, System, Objective Spirit.

\section{Introdução}

Aproximar-se da Filosofia do Direito de Hegel assim como de qualquer outro texto da obra hegeliana, implica em reconhecer que nenhum texto pode ser plenamente compreendido de forma isolada.

A linguagem e as pré-condições sistemáticas inibem uma compreensão fácil. $\mathrm{O}$ esforço que se faz para entender um texto de Hegel invariavelmente deixa o leitor com a impressão de estar diante de um enigma, pois mesmo aí o sentido do todo está presente e se faz notar e exige a compreensão com o alcance desse mesmo todo.

A afirmação hegeliana do Prefácio da Fenomenologia do Espírito de que a verdade é o todo vale também para o todo de uma parte do sistema como a Filosofia do Direito.

A compreensão do todo não se relaciona somente com a dimensão exterior ou com as dadas categorias umas com as outras. Uma compreensão de toda a verdade somente se dá a partir do fim da obra. Essa é a reação de Hegel ao pedido de seu editor para um prefácio à Fenomenologia do Espírito. De certa forma cada texto de Hegel se caracteriza como um prefácio que somente à luz da totalidade do sistema pode ser adequadamente compreendido e ter sua verdade revelada. Por outro lado, fazem parte 


\section{Pedro Geraldo Aparecido Novelli}

dessa totalidade inúmeros momentos que já se apresentam como o processo de descoberta da verdade. A apropriação do todo da Filosofia do Direito deve tomar lugar, dessa forma, através de dois níveis de natureza linear e integral. A totalidade desse processo está contida igualmente em todos os níveis de apresentação enquanto conteúdo do conceito de liberdade como desdobramento e forma segundo uma lógica prática.

Isso significa que para uma interpretação introdutória a leitura sucessiva dos parágrafos não seria muito útil. Seria mais significativa uma visão panorâmica da sistemática da Filosofia do Direito, isto é, sua posição no todo do sistema hegeliano e as consequências daí derivadas como sua relação com a Filosofia do Espírito e a Lógica.

Na Filosofia do Direito Hegel se apropria da tradição científica através da consideração do conteúdo existente sendo essa uma característica fundamental de seu sistema. $\mathrm{O}$ começo pelo direito abstrato e respectiva análise pode ser tomado como uma crítica imanente de Hegel às concepções tradicionais de direito natural e da ciência do Estado. A crítica hegeliana não se quer exterior ou de fora em relação às concepções existentes.

Por isso, não se deve pretender apressadamente distinguir a filosofia das outras ciências com frases ou leis próprias ou ainda com uma relação exterior de proximidade, isto é, paralela sendo a crítica filosófica apartada da própria realidade ou do que ocorre.

A diferença entre a abordagem filosófica e as demais ciências é posta por Hegel em sua Enciclopédia na qual a unidade sistemática se opõe à ordenação exterior.

\footnotetext{
A Enciclopédia filosófica distingue-se de uma outra enciclopédia - a enciclopédia ordinária - porque esta deve ser, digamos, um agregado das ciências, que são acolhidas de modo contingente e empírico, e entre as quais há algumas que de ciências têm apenas o nome, embora elas mesmas sejam uma simples coleção de conhecimentos. A unidade em que, num tal agregado, as ciências se juntam - já que são acolhidas de maneira exterior - é uma unidade igualmente exterior: uma ordem. Essa ordem deve necessariamente, pelo mesmo motivo e também porque os materiais são de natureza contingente, permanecer um ensaio, e apresentar sempre lados inadequados. (HEGEL, $1995, \S 16)$
}

Portanto, não se trata de assumir o dado material ou natural como imanente que as ciências tradicionalmente situam no campo da exterioridade, mas de reconstruir ou racionalizar este dado. Somente assim, segundo Hegel, a natureza ou o dado material será, de fato, sistematicamente objetivo. 


\section{Pedro Geraldo Aparecido Novelli}

\section{Filosofia como Trabalho de Reconstrução}

O sistema de Hegel diferencia-se, por isso, de todos os outros segundo a perspectiva de sistematização do método das ciências empíricas.

Hegel nega as ciências singulares como uma figura da verdade e a mesma postura é aplicada à ciência do direito (cf. HEGEL, 1995, § 16).

Por isso, a tarefa da filosofia é ordenar as afirmações, os teoremas, etc da ciência do direito ou as categorias encontradas da doutrina do direito natural numa estrutura racional universal.

Os objetos particulares serão desenvolvidos no sistema do todo, segundo um universal, na medida em que forem situados no sistema da ciência filosófica. Desse modo, os resultados obtidos pelas ciências singulares precisam ser postas num ramo de fundamentação universal. Cada ciência contribui, enquanto momento, para a construção do todo e tem sua singularidade afirmada nesse mesmo todo que é o objetivo da ciência filosófica ou da filosofia como ciência.

Nesse sentido Hegel assume que o método ou a forma que busca representar os objetos e ser a expressão de cada um deles é a própria expressão do objeto mesmo. (cf. HEGEL, 2000, § 2)

A mediação de leis, categorias, etc., será assim compreendida como se elas permanecessem em uma relação de necessidade entre elas; como momentos de um sistema unitário que contém os resultados científicos singulares que as torna objetos da ciência filosófica.

\section{A Filosofia do Direito de Hegel enquanto momento da Filosofia do Espírito}

O sistema hegeliano funda-se num conceito de ciência que assume a unidade da ciência como movimento do Espírito ou da idéia.

Em si o Espírito contém todos os momentos quase embrionários em si: o Espírito deve também por si tornar-se, si por si, provar-se, fazer-se objetivamente ou objetivo.

$\mathrm{Na}$ linha da representação científica o Espírito se aliena, para que essa diferença de si mesmo ou a oposição de si mesmo, para se encontrar novamente. Ele agora, após sua alienação e oposição é em si e por si; como unidade da imediata (em si ser) e mediadora (em e por si ser ou saber-se) identidade. Assim, o Espírito é a idéia e, esta, apresenta-se como um sistema de figuras ou manifestações (HEGEL, 1995, § 18).

\begin{tabular}{|c|c|c|c|c|}
\hline Qevista Dialectus & Ano 2 & n. 3 & Julho-Dezembro 2013 & p. $18-34$ \\
\hline
\end{tabular}




\section{Pedro Geraldo Aparecido Novelli}

\section{Filosofia do Espírito}

$\mathrm{Na}$ filosofia da natureza e do espírito enquanto sistema das ciências reais e especiais assume Hegel os objetos da ciência contemporânea e os afirma numa forma própria com um lugar específico. Assim dimensiona a filosofia da natureza a matemática e a física do inorgânico e do orgânico e a filosofia do espírito, a antropologia, psicologia, direito, arte, religião e filosofia.

A filosofia do espírito, em Hegel, divide-se novamente em espírito subjetivo, objetivo e absoluto cujas denominadas ciências, e respectivos objetos são ordenados em modo particular.

No espírito absoluto a Enciclopédia atinge seu ponto mais alto e último nível, enquanto determinação final - após a arte e a religião - a filosofia se firma. (Igualmente o nível do Estado na Filosofia do Direito constrói-se na mesma medida resultado e précondição da Enciclopédia, cujo sistema todo é o sistema das ciências filosóficas, isto é, a filosofia.)

A Filosofia do Direito ou a filosofia social hegeliana sedimenta-se como espírito objetivo entre o espírito subjetivo e o absoluto. "Este manual é o desenvolvimento mais completo e mais sistemático das ideias fundamentais sobre o mesmo assunto expostas na Enciclopédia das Ciências Filosóficas que dediquei também ao ensino.” (HEGEL, 2000, p. 23).

\section{Espíritos Subjetivo e Objetivo}

Hegel apresenta inicialmente com as figuras do espírito subjetivo todas as formas da racionalidade ligadas à consciência e, em seguida, as formas de exteriorização do espírito objetivo que se traduzem nas instituições.

O todo dessa parte do sistema e a progressão categorial nele devem ser exteriorizações do Espírito em sentido prático ou relação de vontade - expressão do espírito enquanto vontade.

Hegel diferencia na parte do sistema do espírito subjetivo ambas as figuras do espírito teórico e prático.

\begin{tabular}{|l|l|l|l|l|}
\hline Qevista Dialectus & Ano 2 & n. 3 & Julho-Dezembro 2013 & p. 18-34 \\
\hline
\end{tabular}




\section{Pedro Geraldo Aparecido Novelli}

No espírito teórico “domina o impulso do saber, a busca pelo conhecimento. Do conteúdo do conhecimento eu sei, que ele é, tem objetividade - e também, que ele em mim, então é subjetivo.” (HEGEL, 1995, § 443).

A inteligência ou o espírito teórico enquanto vontade vai á esfera do espírito subjetivo para a objetivação de sua interioridade; o espírito prático, por sua vez, se exterioriza no empenho, para realizar os fins próprios e interesses como impulso, arbítrio, sentimento prático etc e esforço universal, e na linha do espírito prático, constrói seu bem.

Somente o espírito livre como determinação final da esfera do espírito subjetivo na Enciclopédia pode representar a necessária passagem lógica ao espírito objetivo, isto é, ao ponto de saída para a Filosofia do Direito.

A falta do espírito prático existe, por isso, para Hegel, no fato de que a arbitrariedade somente é subjetiva e, portanto, expressão da vontade (HEGEL, 1995, § 478), a felicidade como fim abstrato, não pode afirmar a universalidade real, que ela enquanto subjetividade imediata não é universalizada.

A vontade real livre ou o espírito livre ao contrário constrói a unidade do espírito teórico e prático na medida em que, ele "livre se sabe e se quer como objeto de si" (HEGEL, 1995, § 482).

Saber-se livre e como livre querer-se constrói para Hegel a necessidade da universalidade, que ao espírito enquanto livre contra toda acidentalidade, particularidade, etc caracteriza o espírito subjetivo imediato.

Como resultado da esfera do espírito subjetivo na Enciclopédia o espírito livre ou a vontade livre tem a si mesmo (HEGEL, 1995, § 48) que se deseja como singularidade imediata; na área do espírito objetivo Hegel quer agora começar com a "relação do singular á vontade singular", pela qual o direito abstrato constrói o começo da Filosofia do Direito. Assim, o espírito livre ou a vontade livre caracteriza o ponto de partida da Filosofia do Direito. (HEGEL, 1995, § 483)

O que Hegel até o momento sustenta, que os singulares "são autoconsciência diferente e particular", é que a Filosofia do Direito situa-se na continuidade da filosofia do espírito.

A liberdade, configurada em efetividade de um mundo, recebe a forma da necessidade, cuja conexão substancial é o sistema das determinações da liberdade, e cuja conexão fenomênica é como potência, o ser reconhecido, isto é, seu vigorar na consciência. (HEGEL. 1995, § 484) 


\section{Pedro Geraldo Aparecido Novelli}

Essas figuras da vontade livre como ela se apresenta na Filosofia do Direito, no contrato, no direito como lei, etc., estabelecem na parte do sistema do espírito subjetivo a consciência desenvolvida.

$\mathrm{Na}$ esfera do espírito objetivo relaciona-se a teoria do reconhecimento recíproco (que na formação do espírito subjetivo que compreende um movimento interior - "elas se reconhecem como se reconhecendo reciprocamente" (HEGEL, 2005, § 184) do reconhecimento de uma coisa exterior como a propriedade ou o contrato: como pessoa (ocupante, proprietário, contratante) é assim, que eu somente sou no outro, com o outro e pelo outro (HEGEL, 1995, § 490)).

A vontade tem nessa esfera seu ser aí na coisa, realiza-se sobre uma coisa exterior ou dito de outra forma, a coisa como meio das próprias pessoas igualmente umas com as outras (HEGEL, 1995, § 491), constrói a expressão objetiva desse movimento de reconhecimento; ou seja, por exemplo, o contrato expressão do estabelecer exterior do reconhecimento igualmente universal das pessoas como proprietárias.

O exemplo poderia mostrar, que algo vale na base do reconhecimento através da consciência objetiva, por outro lado esse reconhecimento constitui a realidade exterior. Para essas estruturas estabelecidas ou instituições novamente mostra-se, que se elas devessem ser reconhecidas, de outra forma não teriam elas validade alguma.

Como o espírito só é real no que tem consciência de ser; como o Estado, enquanto espírito de um povo, é uma lei que penetra toda a vida desse povo, os costumes e a consciência dos indivíduos, a Constituição de cada povo depende da natureza e cultura da consciência desse povo. É nesse povo que reside a liberdade subjetiva do Estado e, portanto, a realidade da Constituição. (HEGEL, 2000, § 274)

O reconhecimento universal da instituição - expressão da vontade objetiva baseia nessa condição - na qual tem validade, isto é, a vontade subjetiva.

O conceito de Hegel das vontades subjetiva e objetiva é, dessa forma, não linear, ou seja, no sentido de compreender que uma segue a outra. A vontade objetiva suprassume a falta do subjetivo ao se relacionar à arbitrariedade como não universal, na qual ela, nas instituições enquanto sabida e querida, relaciona-se como algo universal; isso é possível, sendo ambas em princípio da mesma forma, isto é, como figuras que serão compreendidas no espírito universal, ou seja, no sistema da filosofia do espírito (HEGEL, 1991, § 387, Adendos). 


\section{Pedro Geraldo Aparecido Novelli}

A ideia da unidade do subjetivo e do objetivo esclarece uma vez mais que Hegel pensa ambos os polos enquanto unidade, enquanto relação concomitante do reconhecer e do reconhecido.

\section{Espírito Objetivo e Absoluto}

O progresso do espírito objetivo e absoluto na Enciclopédia relaciona sua necessidade à ideia básica que o espírito a si deve vir, pois o espírito objetivo constrói aí um momento sobre esse caminho.

O espírito objetivo é condição objetiva como figura do espírito absoluto que não será, porém, superada então através desse próximo nível que o espírito universal, pois este não se encontra mais na sua pura objetividade.

O espírito deve, para ser livre, e com isso ser absoluto, simplesmente relacionarse consigo mesmo e se ter como seu próprio objeto. Desse modo, a liberdade é o fím e o fundamento do movimento do espírito. "A substância do espírito é a liberdade, isto é, o não-ser-dependente de um Outro, e referir-se a si mesmo.” (HEGEL, 1995, § 382, Adendos)

O espírito na figura do espírito objetivo, enquanto vontade objetiva, mas que já se manifesta na determinação da verdade, liberdade, enquanto substância assume já uma forma determinada.

O espírito enquanto vontade, que somente a si se quer, então enquanto vontade absoluta, deve construir na figura da eticidade com a determinação final do Estado o nível mais alto e afirmativo.

$\mathrm{Na}$ linha do espírito objetivo relaciona-se o espírito enquanto vontade absoluta somente consigo enquanto fim sabido, permanece, porém, uma realidade exterior ligada, isto é, não se ocupa senão com outro como o faz consigo. Aqui a liberdade tem sua compreensão específica enquanto efetividade no espírito objetivo. Pois: "Nesse caminho da libertação, incide a finitude do espírito. Pois, enquanto o espírito não atingiu a sua meta, não se sabe ainda absolutamente idêntico com seu objeto, mas se acha limitado por ele.” (HEGEL, 1995, § 441)

Somente na esfera do espírito absoluto retorna a ideia a si de seu outro, pois assim o espírito sabe de si como absoluto livre.

A interioridade do espírito afirma sua real liberdade, pois aí ele sabe e quer, mas esse nível não pode ser atingido senão pela sua objetivação na exteriorização ou

\begin{tabular}{|l|l|l|l|l|}
\hline Qevista Dialectus & Ano 2 & n. 3 & Julho-Dezembro 2013 & p. 18-34 \\
\hline
\end{tabular}


estabelecimento da vontade livre. $\mathrm{Na}$ exterioridade o espírito supera seu enclausuramento, pois nem em seu ensimesmamento nem sem seu sair de si pode ser de fato livre. Na objetivação do espírito sua finitude ou historicidade revelam sua deficiência cujo desenvolvimento progressivo força o nível seguinte para a figura do espírito absoluto ou do reino da verdadeira liberdade.

Também serão concebidas nesse nível as figuras singulares (arte, religião, filosofia) no sentido de crescente independência do espírito; somente o nível final da Filosofia como ciência encarna a liberdade do espírito de maneira completa.

Desde sua perspectiva, a perspectiva da verdade ciente de si ou infinito e eterno (HEGEL, 1995, § 574), pode o espírito absoluto primeiramente diferenciar o que é no nível do sistema do espírito objetivo finito e o que é essencialmente racional.

Pode-se dizer que a representação de Hegel da determinação de liberdade indica mostrar o espírito ao nível do espírito objetivo que faz a liberdade o objeto de sua vontade num mundo exterior; ao nível do espírito absoluto a liberdade, ao contrário, é objeto da vontade como ciência. Esse nível do espírito absoluto fica fundado, portanto, na representação científica de todos os outros sistematicamente.

Sob o ponto de vista da teoria da liberdade hegeliana uma teoria da liberdade do espírito será compreendida, a partir da determinação final da Enciclopédia, ao nível prévio, como expressão incompleta da liberdade. O pensamento filosófico da liberdade pode meramente determinar-se livre, na realidade exterior a realização da liberdade posta é o estabelecimento de limites.

\section{Arquitetura da Filosofia do Direito}

Até o momento procurou-se situar a Filosofia do Espírito no campo do espírito objetivo no sistema filosófico hegeliano. Cabe agora considerar sua relação com a Lógica que Hegel aponta já no início dos “Grundlinien” ou Princípios.

\section{Lógica e Filosofia do Direito ou a Lógica da Filosofia do Direito}

No prefácio da Filosofia do Direito Hegel indica que ele pré-estabelece que o modo filosófico do progresso de uma matéria à outra e principalmente a prova científica diferencia-se de outra forma de conhecimento e que a natureza do saber especulativo ele teria desenvolvido em sua Ciência da Lógica (HEGEL, 2000, p. 24). A possibilidade

\begin{tabular}{|l|l|l|l|l|}
\hline Qevista Dialectus & Ano 2 & n. 3 & Julho-Dezembro 2013 & p. 18-34 \\
\hline
\end{tabular}




\section{Pedro Geraldo Aparecido Novelli}

indicada por Hegel é a de ciência da liberdade, pois esta pode não somente ser pensada, mas também determinada.

O conhecimento dessa obra, cuja forma resumida Hegel apresenta na Enciclopédia como método do todo, torna possível primeiramente a compreensão sistemática da Filosofia do Direito; a interdependência lógica representa no próprio tratado para seu autor o ponto central de relação à possível crítica. "O direito, a moralidade e a realidade jurídica e moral concebem-se através de pensamento, adquirem a forma racional, isto é, universal e determinada, por meio de pensamento." (HEGEL, 2000, p. 31)

Essa relação da forma e do conteúdo do objeto científico permite também somente indicações comentadas sobre o método na representação, como nós as encontramos espalhadas ao final da Filosofia do Direito numa grande parte subordinada do sistema. Hegel avança ao ponto de que o método da representação na própria evolução da representação se dá enquanto método já como objeto da Lógica ou para ser objeto da Lógica. O método e o objeto se dão um ao outro. O método já é um objeto e o objeto já é um método. O método que se antecipa ao objeto não conhece o objeto, mas conhece como conhece o objeto. O método que conhece o objeto é que se faz ao se fazer. O caminho se faz no caminhar. O método a priori é condicionador, inibidor. $A$ posteriori é condicionado, mero tradutor.

\section{A Lógica como forma da Ciência}

Até aqui ficou posto que a verdade de um objeto ou do objeto é concebida como auto- movimento.

Ao mesmo tempo afirma Hegel esse movimento como método universal que todos os objetos resultam de tal forma ou expressão científicas. (HEGEL, 1968, p. 29)

O método, enquanto construção do todo em sua pura essencialidade posta (HEGEL, 2005, § 48) constrói o objeto da Lógica como obra. O deslocamento de um objeto se dá, segundo Hegel, sozinho "como o desenvolvimento de toda vida natural e espiritual, da natureza da pura essencialidade que faz o conteúdo da Lógica" (HEGEL, 1968, p. 29); isto é, para nossa interdependência, se se furta aqui da dimensão ontológica desse conceito, tanto quanto na medida em que a Lógica da Ciência (HEGEL, 1968, p. 28) pressupõe todos os objetos da Enciclopédia. (cf. HEGEL, 2000, $\S 31)$

\begin{tabular}{|l|l|l|l|l|}
\hline Qevista Dialectus & Ano 2 & n. 3 & Julho-Dezembro 2013 & p. 18-34 \\
\hline
\end{tabular} 


\section{Pedro Geraldo Aparecido Novelli}

Ao contrário, deve-se assumir que o conteúdo especial, ou seja, cujo desenvolvimento imanente, somente segundo a maneira possível singular pode desenvolver, a Lógica é sempre o conteúdo dessa forma universal. “Também o caráter lógico da ideia absoluta pode se chamar uma de suas maneiras, porém, enquanto que a maneira indica uma espécie particular, uma determinação da forma, vice-versa o caráter lógico é a maneira universal, em que todas as maneiras particulares estão eliminadas e envolvidas." (HEGEL, 1968, p. 726)

Até o momento pode-se ver como Hegel pensa o mundo como ideia cuja representação científica enquanto passagem sistemática do espírito; que não pode ser para além disso sistema de caráter científico. Assim o método lógico:

(...) tem que ser reconhecido como uma maneira ilimitada, universal, interna e
externa, e como a força absolutamente infinita, a que nenhum objeto, enquanto
se apresente como exterior, afastado da razão e independente dela, poderia
oferecer resistência, isto é, conservar frente à ela uma natureza particular e
recusar-se a ser compenetrado por ela. Por isso, o método é a alma e a
substância, e qualquer coisa é concebida e conhecida em sua verdade somente
quando está totalmente submetida ao método; este é o método próprio de cada
coisa, porque sua atividade é o conceito. (HEGEL, 1968, p. 727)

É necessário considerar a interdependência entre método e conteúdo na Lógica que se divide entre a lógica do ser, da essência e do conceito.

Essa estruturação relaciona-se também à concepção de filosofia do espírito.

A Filosofia do Direito ergue-se sobre uma mesma estrutura: a lógica do ser = direito abstrato; lógica da essência $=$ moralidade e lógica do conceito $=$ eticidade .

Não se trata, contudo, de uma estruturação mecânica, mas sim uma necessidade que historicamente se põe.

A Ciência da Lógica mostra que a Lógica objetiva representa a forma do conteúdo subjetivo e, além disso, a Lógica objetiva prepara o absoluto da Lógica.

Essa estrutura repete-se na Filosofia do Direito expressa pelos níveis objetivos da relação da vontade subjetiva.

$\mathrm{Na}$ parte referente ao Direito abstrato, a esfera da concebida lógica do ser da Filosofia do Direito, na qual a vontade livre se dá como ser aí (cf. HEGEL, 1991, § 487), Hegel fala de juízo negativo, positivo e infinito da vontade sobre a coisa, quando ele caracteriza as determinações próximas da propriedade, ou seja, uso e venda.

Hegel entende a apresentação da vontade como nível de passagem concebido análoga à apresentação da ideia na Lógica - de cujo ser abstrato imediato, sobre a reflexão desse ser como essência ou verdade, ambas se desenvolvem ao conceito que é como mediação de ambas.

\begin{tabular}{|c|c|c|c|c|}
\hline Qevista Dialectus & Ano 2 & n. 3 & Julho-Dezembro 2013 & p. $18-34$ \\
\hline
\end{tabular}




\title{
Pedro Geraldo Aparecido Novelli
}

Ao mesmo tempo será subordinada a vontade abstrata imediata inicial já como momento da vontade universal concreta; porém essa subordinação segue do alto nível do espírito absoluto que Hegel concebe até para a Filosofia desse método particular (Lógica do Conceito). A vontade é, consequentemente, ao mesmo tempo, do início à subjetividade caracterizada pela competência conceitual lógica.

\section{Para o método da Filosofia do Direito}

A lógica especulativa da Filosofia do Direito é enquanto lógica do espírito objetivo, lógica da vontade e de suas figuras.

O conceito da vontade livre e seus momentos são assim descritos por Hegel:

\begin{abstract}
O domínio do direito é o espírito em geral; aí, a sua base própria, o seu ponto de partida está na vontade livre, de tal modo que a liberdade constitui a sua substância e o seu destino re que o sistema do direito é o império da liberdade realizada, o mundo do espírito produzido como uma segunda natureza a partir de si mesmo." (HEGEL, 2000, § 4)
\end{abstract}

As figuras da vontade objetiva são as instituições e sua substância, a liberdade. $\mathrm{O}$ progresso de um nível a outro será apropriado por Hegel ao progresso na Lógica como progresso do abstrato ao concreto, ou seja, trata-se da saída do abstrato e progresso para a sempre mais rica determinação até seu resultado, que como fundamento ou unidade do movimento de tudo até a decisiva determinação desenvolvida. (HEGEL, 1991, § 408, Adendos)

Cada momento da vontade ou da liberdade é com isso necessário para o progresso na representação, cuja deficiência é, que promove o nível seguinte, de modo que fundamenta a necessidade sistemática linear que o momento seguinte, segundo a unidade desse momento ocorrido constrói, também contribuindo ao mesmo tempo para uma estrutura de movimento circular.

Com isso compreende o nível interno alcançado da unidade do progresso não somente como conteúdo mais rico, mais alto ou completo (em sentido quantitativo), mas também constrói um conteúdo novo do constituinte. Esse movimento tem sucesso na medida em que a liberdade reconstrói numa maneira completa, até que um patamar é atingido.

O percurso do nível da Filosofia do Direito segue o que também se dá formalmente na Lógica pela unidade do ser, da essência e do conceito. 


\title{
Pedro Geraldo Aparecido Novelli
}

Cada nível singular preenche esse movimento do próprio imediato à afirmação ou realização plena através do próximo.

Como exemplo final deve ser demonstrada a passagem do direito abstrato ao progresso da moralidade.

\begin{abstract}
$\mathrm{Na}$ esfera do direito, a vontade existe em algo exterior, mas a próxima exigência é que a vontade deveria ser existente em algo interior em si mesma. A vontade deve a seus próprios olhos ser subjetividade e ter a si mesma como objeto. Essa relação consigo mesma é o momento da afirmação, mas somente pode ser obtida se suprassumir sua imediaticidade. A imediaticidade suprimida no crime conduz, então, através da punição, isto é, através da negação da sua negação, à afirmação, ou seja, a moralidade. (HEGEL, 2000, § 104, Adendos)
\end{abstract}

A dupla negação lógica do movimento de nível a nível avança até que ela assuma o nível mais alto da eticidade em seu próprio fim. O significado especial do Estado se dá sempre no seu vir a ser.

O Estado é por um lado autodeterminação ou momento da vontade livre ou da liberdade, uma novidade no desenvolvimento linear.

No Estado reside o princípio teórico da solução promovida que na sociedade civil permanece insolúvel, nomeadamente a representação da afirmatividade. O Estado estabelece de antemão a sociedade civil que mesmo assim permanece como algo singular.

O Estado enquanto determinação em sistema de momentos que se põem lado a lado tem sua própria dignificação ou conforme Hegel seu direito singular. No direito o Estado é particularmente afirmado, porém essa não é sua última e única afirmação.

Pode-se compreender a teoria hegeliana em sua relação com outras determinações nesse sentido que será um momento da liberdade, mas não momento exclusivo.

O Estado como inclusão das determinações existentes, isto é, enquanto unidade, tem que assegurar também a característica sistemática, a afirmação do movimento no interior da parte do sistema do espírito objetivo, o progresso da determinação para com isso chegar a uma conclusão.

Somente ao final da teoria é que se prova que o direito e a moral têm sua base nas instituições da esfera ética. A necessidade sistemática exige que se mostre no próprio conteúdo, não somente como algo que se asseguraria. Direito e moralidade, enquanto bases da filosofia prática, se tomados por si mesmos serão criticados por Hegel como imanência dada. 


\section{Pedro Geraldo Aparecido Novelli}

\section{Conclusão: O prefácio da Filosofia do Direito}

“Como Prefácio apenas pretendeu indicar, exterior e subjetivamente, o ponto de vista do escrito que precede.” (HEGEL, 2000, p. 39)

A representação filosófica mesma representa o tratamento científico e objetivo do conteúdo da Filosofia do Direito.

No início Hegel apresenta o conceito de base da Filosofia do Direito e sua posição no sistema das ciências filosóficas.

O primeiro motivo que me levou a publicar este esboço foi a necessidade de oferecer aos meus ouvintes um fio condutor para as lições que oficialmente ministro sobre a Filosofia do Direito . Este manual é o desenvolvimento mais completo e mais sistemático das idéias fundamentais sobre o mesmo assunto expostas na Enciclopédia das ciências filosóficas que dediquei também ao ensino (Heidelberg, 1817) (HEGEL, 2000, p. 23).

Em seguida ele diferencia seus Princípios do direito natural e da ciência do Estado. A menção maior é a do método da Filosofia do Direito.

(...) que, desde logo, diferencia este ensaio de um resumo é o método que o dirige. (...) Na minha Ciência da Lógica desenvolvi completamente a natureza do saber especulativo. Queria eu, todavia, que se considerasse e julgasse este tratado tendo em especial atenção este aspecto, pois aquilo de que se trata é a ciência e na ciência o conteúdo encontra-se essencialmente ligado à forma. (HEGEL, 2000, p. 23-24)

A Filosofia do Direito encontra-se em ligação direta com a Lógica ou modo de conhecer especulativo. A importância disso reside na diferenciação de outras formas de filosofia que não se constituem como ciência. Forma e conteúdo devem se completar e a verdade é plena se se dá em ambas. A verdade filosófica de um conteúdo pode somente expressar essa ligação formal; verdades em sentido de significado, ao contrário, serão descobertas, ditas e espalhadas. Essa multidão de verdades conduz para Hegel ao cancelamento da forma que é o contrário da ciência.

Hegel se esforça por tratar o conhecido ou dado sobre o Estado, o direito, a eticidade como a tarefa da filosofia, para descobrir algo novo ou como Penélope que diariamente reinicia seu trabalho começando do nada.

A tarefa do espírito pensante é, porém em distinção a outras formas de procedimento, não pelo dado estático, senão pelo conceituar e estabelecer na forma do conceito (HEGEL, 2000, p. 26). Determinar a substância do direito ou do ético sistematicamente, é a tarefa de uma filosofia do direito. 


\section{Pedro Geraldo Aparecido Novelli}

Hegel critica as formas contemporâneas, no reconhecer público que ao invés de fazer do objeto esclarecimento somente faz teoria para criticar o objeto, porém para a expansão da filosofia, ela deveria encontrar novas teorias sobre o Estado.

Que as instituições do mundo ético de Hegel serão compreendidas como sabidas e quistas, o passo seguinte torna claro que mesmo quando não se quer e nem se reconhece o Estado é o fundamento primeiro e último de toda e qualquer instituição e de tudo o que cada uma delas objetiva e representa.

Não somente o desconhecimento do mundo ético senão também a compreensão continuada que o verdadeiro não pode se reconhecer por si, para Hegel; permanece sob a intenção, de que o Estado, o governo e a constituição fundam-se sobre o coração, a natureza e a fascinação.

Colocar a determinação da liberdade sobre o sentimento (HEGEL, 2000, p. 30) que se dá pela racionalidade e conhecimento, aparece para Hegel como não filosófico e irracional. Ele sabe, como expressa o ditado de Fausto sobre as consequências possíveis de um tal irracionalismo. Nem através do sentimento nem através da justiça são apreendidos o mundo ético e o Estado em sua arquitetônica da racionalidade, senão somente através do pensamento (cf. HEGEL, 2000, p. 30).

A relação de confiança prejudicada entre Filosofia e governo é em seguida tratada por Hegel.

Hegel compara nesse contexto sua crítica anterior aos já citados filosofemas de Platão no Sofista; também cujo princípio seria "que, o que o direito é, fica sobre os fins e significados subjetivos e sobre o sentimento subjetivo e o convencimento particular", enquanto a filosofia deve ir para o princípio universal do reconhecer universal e válido.

Hegel repete uma vez mais, que a negação da universalidade da existência tem como consequência a negação da reconhecibilidade da verdade.

O lugar da filosofia para a efetividade com o famoso ditado 'O que é racional, é real e o que é real é racional' constrói o próximo ponto de argumentação.

A apreensão do presente e do real previne que a filosofia construa a realidade, como ela deveria ser. Ao mesmo tempo, enquanto fundamentação do racional, ela não se ocupa com a multiplicidade empírica das formas de aparência histórica nem com a riqueza de formas, aparências e figurações (críticas a Kant e Fichte), senão que se relaciona com seu lado essencial.

Esse lado substancial ou racional Hegel quer almejar conceituar e representar com a Filosofia do Direito. Na medida em que a Filosofia do Direito contém a ciência

\begin{tabular}{|c|c|c|c|}
\hline Qevista Dialectus & Ano 2 & n. 3 & Julho-Dezembro 2013 \\
\hline
\end{tabular}




\section{Pedro Geraldo Aparecido Novelli}

do Estado, ela não visa construir um novo Estado, Hegel não se detém numa utopia ou em ensinar como um Estado deve ser, senão muito mais representar como ele deve ser reconhecido.

Esse reconhecer do racional na realidade possibilita segundo Hegel igualmente a reconciliação com a realidade que também é contingente e assim irracional. Entre a razão como espírito consciente de si e a razão objetiva da realidade é mediado o reconhecer científico que liberta a razão objetiva no conceito.

Hegel acentua com esse conceito mais uma vez o que já havia sido dito anteriormente, ou seja, que o pensamento é a identidade entre forma e conteúdo da ciência e estende aqui sua determinação da forma para a razão como reconhecer conceitual, e do conteúdo para a razão como essência substancial do ético assim como da realidade natural. A ideia filosófica constrói a identidade consciente de ambas.

Finalmente, limita Hegel o poder do espírito de certa forma e no seu objeto apropriado a sua valência singular, a filosofia pode do mesmo modo, como o indivíduo, cuja existência será vista como finita, ir além de seu tempo; ela pode 'simplesmente' reconhecer o mundo e poderia querer ensiná-lo como ele deve ser, assim chegaria sempre atrasada, porém ela somente pode se relacionar com o já 'sido-tornado' ou o que se fez .

Quando a filosofia chega com a sua luz crepuscular a um mundo já a anoitecer, é quando uma manifestação de vida está prestes a findar. Não vem a filosofia para a rejuvenescer, mas apenas reconhecê-la. Quando as sombras da noite começaram a cair é que levanta vôo o pássaro de Minerva. (HEGEL, 2000, p. 39)

\section{Referências}

HEGEL, G. W. F. Ciencia de la Lógica. Trad. de Rodolfo Mondolfo. Buenos Aires. Solar S.A. / Hachette S.A., 1968.

Enciclopédia das Ciências Filosóficas em Compêndio (1830). Trad. de Paulo Meneses. São Paulo: Loyola, 1995.

Fenomenologia do Espírito. $3^{\mathrm{a}}$ ed. Trad. de Paulo Meneses. Petrópolis: Vozes, 2005.

Grundlinien der Philosophie dês Rechts. Red. Von Eva Moldenhauer und Karl Markus Michel. Frankfurt am Main: Suhrkamp, 2000. 
Princípios da Filosofia do Direito. Trad. de Orlando Vittorino. São Paulo: Martins Fontes, 2000.

1989.

Propedêutica Filosófica. Trad. de Artur Morão. Lisboa: Edições 70, 